\title{
An empirical analysis of perceived significance of information security service quality to predict the organisational performance in software service industry
}

\author{
Sanjay Bahl • O. P. Wali
}

Received: 13 February 2013/Accepted: 22 June 2013/Published online: 5 July 2013

(C) CSI Publications 2013

\begin{abstract}
Businesses have derived various benefits from offshore outsourcing of information and communication technology services while accepting and managing perceived risks with respect to the service quality of information security delivered in the supply chain. In this empirical research, taking India as a case which tops the global information technology outsourcing supply chain world ranking, we examine the perceptions of Indian software services provider (service provider) employees with respect to information security service quality delivered to customers and its impact on the service provider organisational performance. Using the existing dimensions and instruments for service quality and organisational performance, our study provides a framework suitably modified to reflect the context of information security. We have used SmartPLS, a structural equation modeling technique, to analyse field survey data collected from across different Indian cities and companies. Significant finding of our research is that information security service quality in an IT offshore outsourcing company providing software services has an impact on the service provider organisation performance, which can be predicted. In addition we also establish that there is positive relationship collectively between elements of information security service quality and organisation performance. We conclude that there is an urgent and serious need for software outsourcing business enterprises to focus on, amplify and commit to information security service quality at strategic, tactical, and operational levels if they wish to achieve revenue expansion, completely satisfied customers and create long term trusted relationships.
\end{abstract}

S. Bahl $(\bowtie) \cdot$ O. P. Wali

Indian Institute of Foreign Trade, New Delhi, India

e-mail: sanjaybahl.pers@gmail.com
Keywords Information security service quality . Information technology offshore outsourcing · Indian software service providers - Supply chain . Organisation performance $\cdot$ Trust relationship

\section{Introduction}

The remarkable increase and dependency on information and communication technologies (ICTs) by businesses to achieve efficiency, collaboration, improved effectiveness and competitiveness has also led to an increasing demand for software services, which can be broken down into their constituent parts and traded [1]. This increased demand has lead to and is fuelling the unstoppable growth of IT outsourcing business [2] and outsourcing is making the world a better place by the redistribution of wealth [3]. As offshore outsourcing service providers and customers continue to innovate and devise new services for outsourcing there is also an increasing challenge for service providers to ensure that they provide assurance and compliance against information security breaches including service failures. Information security assurance along with risk management, quality, financial issues and other factors are essential parameters in selecting an IT outsourcing partner [4]. Few studies have investigated outsourcing issues from the vendor's perspective and there is need of research from an information security perspective in offshore outsourcing context at the vendors end. In this study we empirically investigate whether information security service quality has an impact on software services organisation performance from the offshore outsourcing service provider perspective. We conclude that there is an urgent and serious need for the development of adequate security measures such as information security service quality by the 
service providers if they wish to achieve revenue expansion, completely satisfied customers and create long term trusted relationships.

\section{Theoretical background}

\subsection{Offshore outsourcing}

Rapid advances in the information and communication technology have transformed the way services are traded and have provided tremendous boost to cross border trade in services. This globalisation of services sector has given rise to offshoring - the cross border sourcing of ICT enabled business support services. In the trade of services based on the General Agreement on Trade in Services, four modes to trade services internationally have been identified based on the location of the service provider and customer of the traded service [5]. Offshore outsourcing of software (part of information technology services) is defined as "when the supplier of software development is from another country than the firm that decides to outsource information systems" [6]. A vast body of knowledge exists with respect to outsourcing covering various aspects such as benefits and implications of outsourcing, economic theories, management of key risks during outsourcing, client perspective, relationship perspective, provider perspective, process view to security frameworks for outsourcing [4, 6-20]. Offshore outsourcing of software services is one of the leading strategies followed by majority of business enterprises from developed countries to achieve a competitive lead and achieve efficiency gains while reducing their costs and skills shortage. It is documented in past research that information systems outsourcing is a strategic management practice which is currently going through an unstoppable growth period [13,21] and India is the largest exporter of ICT services in the world [4, 22]. But at the same time there have been questions raised with respect to service quality and information security violations offshore [23].

\subsection{Quality, service quality and information security}

An effective strategic technique which is used to achieve competitive lead by business enterprises is quality [24] and for expanding the offshore outsourcing industry trade bodies indicate quality as a differentiator to the customers [25]. In any relationship between a service provider and customer, quality persists to be an essential aspect as established by [26] in their research. Reliable and consistent quality is the most important dimension in terms of perceived value for customers trust and satisfaction [27]. Causal relationship between trust, long term relationship and role of quality has been established through structural equation analysis by [28].
In a service encounter where the trade of outsourcing software services between customers and the service providers providing software services takes place, the service providers strive to be competitive and a market leader by delivering superior customer value by focusing on three value disciplines (wherein they meet industry standards in two of them and excel in the third) which are operational excellence, product/service leadership and customer intimacy [29]. The outsourcing success of a service provider is dependent on service quality, which is supplying high quality and value added information systems services in the best interest of the customers, and partnership elements like trust [30]. Over the years, extensive and rich literature has been available in the area of service quality. Services are difficult to evaluate as compared to goods/products since they tend to be intangible, the customer is involved in their creation, they are processes and also dependent on the behaviour of the service provider [30]. The most widely accepted and cited service quality model in literature is the GAP model from Parasuraman et al. [31]. Service quality, with respect to this model, is widely defined in published literature as the gap between the service expectation by customers from a service provider and actual service perceived to be delivered to the customer by the service provider. The service quality conceptual framework from Parasuraman et al. [32-35] identifies five dimensions that customers consider in their assessment of service qualityreliability, responsiveness, assurance, empathy and tangibles. A 22 item instrument, popular in literature as SERVQUAL tool is available, which helps to assess the service quality gap between customers' perceptions and expectations and found to be appropriate for measuring information systems service quality [32, 34-38]. The service quality model can be used to study the gap between customer driven expectations and perceptions which are formed based on service providers services and behaviour.

Reference [39] has decomposed quality into its relevant component factors (attributes or characteristics) and established clearly that security along with safety and survivability are quality factors. Information security has been identified as a dimension of information quality and further characterized as dependable information for service quality [40]. The Code of Practice BS7799 for Information Security, also accepted by the ISO in the ISO/IEC 27000 family and also aligned with ISO 9000 (quality management), considers security to be a part of quality as it is based on the continuous improvement "plan-do-check-act" cycle which is used for quality (ISO 9000) and known as the Deming cycle or PDCA [41, 42]. As per Woody [43], security is a quality area, a shared responsibility across the organization, does not have complete requirements and a failure to recognise it is an organisational risk leading to liability. One of the vital selection parameter for selecting 
an offshore outsourcing service provider is information security assurance levels, their effectiveness, efficiency, adequacy at the service provider side and information security is essential for initial and continued outsourcing trust $[4,11,18,20,44,45]$.

\subsection{Performance}

Security breaches can cause a sustained loss in an organisations share price, thus impacting its performance [46]. Lodahl and Redditt [47] point out that "most companies still manage IT to minimize its cost rather than to maximize its contribution" and in their work they found that the information technology "contribution measure accounts for half the variance $\left(R^{2}=0.52\right)$ in company profit margins normalized by industry". In literature, the relationship between quality management practices and organisational performance has been much researched. Understanding and delivering on customers' expectations, is a dynamic business situation requiring continual quality improvement which in turn relates quality practice to improved financial performance (significant at $p<0.01$ ) based on data collected from 977 business firms from across the globe [48]. This is further strengthened by providing empirical evidence that firms after having received quality awards show better operating income-based measures [2] Integrating quality initiatives with the 5P's (Purposes, Principles, Processes, People, and Performance) model helps in providing feedback and control for strategic decision making, based on the performance of an organisation for its long term survivability and profitability [49].

The performance of an organization denotes two aspects-(1) the operational efficiency such as quality improvement having measures such as customer satisfaction which is derived from the business process performance and (2) the improvement of the bottom line such as revenue increase or reducing costs or profitability which are measured based on financial parameters derived from overall organisational performance [50]. A firm's performance, relating to effectiveness, is the action it takes to meet customer demands and quality, including service quality dimensions, has been the main driver for expansion in scope of performance measurement, including operations performance-requiring multiple measures, both financial or monetary and non-financial or value [51-53].

A cross-sectional study by Samson and Terziovski [54] showed that there is a significant relationship between total quality management practice and organisational performance in terms of quality performance, operational and business performance indicators. A key determinant of an organisations success is superior service quality $[55,56]$. In the ever increasing competitive conditions for capturing global software outsourcing business and completely satisfying increasing customer demands, it is inevitable for software service providing organisations to amplify their superior service quality so as to highlight operational efficiencies. To achieve this amplification, the service provider organisations should take responsibility in helping customers perceive the advantage by enhancing their measurement knowledge [57]. Service provider organisations need to understand that, based on research of thirty organisations from five different markets, it should be their top priority to have completely satisfied customers which requires some investment and in return these customers turn out to be very loyal and the investment of the service provider is paid back many times over thus helping drive the long term financial performance of the service provider [58]. In a service industry context financial measures have some limitations and hence performance is enhanced by non-financial measures where decision makers look at causes instead of effects in service operations [59]. The empirical results for financial returns from quality indicate superior outcomes for a customer satisfaction approach which is marketing and leads to revenue expansion as compared to efficiency approach which is operations and leads to cost reduction or as compared to both which is revenue expansion and cost reduction at the same time [60].

Researchers have also provided questions, elements or attributes that they have used for their survey instruments in their research and contribution to organisations operational performance $[51,54,56]$.

\section{Research model and hypothesis}

Since information security is a part of quality, it is also an integral part of service quality. Thus there is a link between information security service quality (based on SERVQUAL) and organisation performance. In our research we have considered the five dimensions of SERVQUAL and two dimensions of performance-monetary and value. With respect to service quality, we have studied the perceptions from employees perspective who are providing the services to customers. The motivation of this research paper is to build upon the existing dimensions and instruments for service quality and performance while modifying them to reflect the context of information security. In addition, this also helps us to ensure the control of measurement error. We have administered these instruments on employees at the Indian software service providers end to study:

The service quality that is followed at the Indian software service providers in terms of their perception of what the customer expects which is ideal and their perception of what they provide which translates to customer perception which is actual, and 
Fig. 1 Conceptual framework

Security Service Quality

Tangibles
Reliability
Responsiveness
Assurance
Empathy

Organization Performance

Monetary

Value
Their perception, with respect to information security, of their organisations performance in monetary and value terms.

The research model for our conceptual framework between information security service quality and organisation performance is in Fig. 1 .

Our assumptions are that information security service quality drives organisation performance based on perceived value for customer trust, long term customer relationship, determining customer satisfaction and building service providers brand identity. Our hypothesis is that:

(1) Quality of security services in an outsourcing company providing software services can predict the organisation performance, and

(2) There is positive relationship collectively between elements of Security service quality and organization performance.

\section{Research design and methodology}

\subsection{Research design and sample}

Our study has used survey methodology to gather data. The target audience was security professionals in the Indian software service provider companies. We received responses from 61 respondents from 22 companies covering various cities across India where outsourcing software services vendors are situated-Bangalore, Chennai, Hyderabad, Delhi, Noida, Gurgaon, Lucknow, Bhubaneswar, Mumbai, Pune. The data was collected on a Likert scale, where 1 indicated minimum agreement and 7 indicated maximum agreement. The data demographics are as in Table 1

\subsection{Measures of the construct}

We have used measures that have been validated in previous research of SERQUAL and performance to ensure the control of measurement errors. However, we have modified and constructed some measures to reflect the context of information security. Construct validity as well as structural coefficients have been analyzed by SmartPLS
Table 1 Data demographics

\begin{tabular}{ll}
\hline & $\%$ \\
\hline Region & \\
North and East India & 32.78 \\
West India & 19.67 \\
South India & 47.55 \\
Age group & \\
25-30 & 29.5 \\
$31-40$ & 34.43 \\
Above 41 & 36.07 \\
Service years & \\
$1-5$ & 29.5 \\
$6-10$ & 29.5 \\
$11-15$ & 24.6 \\
16 and above & 16.4 \\
\hline
\end{tabular}

[61], a software application for the design of structural equation models.

\section{Data analysis and results: model testing and construct validity}

We have used partial least square (PLS), a structural equation modeling (SEM) technique for modeling. The PLS procedure is a second-generation multivariate technique [62] which has been gaining interest and use among researchers specifically in computer science, management, accounting, marketing, operations management and psychology. PLS is a component based variance analysis method and determines the prediction relevance of latent variables; meaning how well a specific construct value can be predicted by another construct value [63]. Hence PLS is a prediction-oriented model. PLS is similar to regression, but can assess the measurement model and structural model simultaneously in one operation.

PLS has been used since our primary concern is the prediction of dependent endogenous variables-as PLS generates latent variable scores that can be used to predict a model, does not impose homogeneity or normality requirements on the data, can be used to analyze a model that incorporates reflective variables, it is a powerful data analysis technique even when a sample size is small- 
recommendation of a minimum sample size of 40 may be sufficient, can be used for complex and simple models [6468].

In our research we have used the data collected for (1) security service quality through 22 questions for what the employees at the Indian software service providers perceive what the customer expects which is ideal and 22 questions for their perception of what they provide which translates to customer perception which is actual. The break up for the 22 questions in service quality is as follows: 4 for tangibles, 5 for reliability, 4 for responsiveness, 4 for assurance and 5 for empathy. We have provided the results for service quality by taking actual and also by taking ratio of actual to ideal, and (2) organisation performance through 16 questions as follows: 3 for monetary and 13 for value.

\section{Testing of individual item}

Alpha should be greater or equal to 0.80 for a good scale, 0.70 for an acceptable scale, and 0.60 for a scale for exploratory purposes [69]. The average variance extracted (AVE) by each construct should exceed 0.50 to have convergent validity [70]. The criteria for alpha and AVE are met as can be observed in Tables 2 and 3 .

Most of the standardized loadings of individual item were over the acceptable cutoff level of 0.6 [71] (in survey questions - the $2 \mathrm{P}$ notation is used for the service quality and $5 \mathrm{P}$ notation for performance). The only loadings lower

Table 2 Actual

\begin{tabular}{lll}
\hline & AVE & Cronbach's alpha \\
\hline Assurance & 0.746683 & 0.886807 \\
Empathy & 0.592809 & 0.825288 \\
Monetary & 0.843638 & 0.908677 \\
Reliability & 0.596569 & 0.829956 \\
Responsiveness & 0.73194 & 0.87659 \\
Tangibles & 0.525433 & 0.698719 \\
Value & 0.551379 & 0.930441 \\
\hline
\end{tabular}

Table 3 Ratio-(actual to ideal)

\begin{tabular}{lll}
\hline & AVE & Cronbach's alpha \\
\hline Assurance & 0.769987 & 0.900482 \\
Empathy & 0.643411 & 0.861207 \\
Monetary & 0.839901 & 0.908677 \\
Reliability & 0.576366 & 0.813923 \\
Responsiveness & 0.855353 & 0.942979 \\
Tangibles & 0.530499 & 0.715973 \\
Value & 0.543703 & 0.930441 \\
\hline
\end{tabular}

than 0.6 were 0.431327 and 0.516107 but more than 0.4 [72] while being significant as per the $T$ statistics, out of 38 reflective indicators and hence have been considered as acceptable as can be seen in Table 4.

As an example the question 2P1 is: organization has up to date technology and processes for security; the question 2P8 is: they adhere to meeting security services (physical, network, application, people as required contractually) at the times they promise to do so; the question $2 \mathrm{P} 22$ is: the

Table 4 Loading values

\begin{tabular}{|c|c|c|}
\hline & Original sample & $T$ statistics \\
\hline $2 \mathrm{P} 1 \leftarrow$ tangibles & 0.852299 & 24.493884 \\
\hline $2 \mathrm{P} 10 \leftarrow$ responsiveness & 0.743990 & 11.405581 \\
\hline $2 \mathrm{P} 11 \leftarrow$ responsiveness & 0.904114 & 42.247984 \\
\hline $2 \mathrm{P} 12 \leftarrow$ responsiveness & 0.910618 & 37.264586 \\
\hline $2 \mathrm{P} 13 \leftarrow$ responsiveness & 0.839591 & 27.629891 \\
\hline $2 \mathrm{P} 14 \leftarrow$ assurance & 0.908007 & 50.664170 \\
\hline $2 \mathrm{P} 15 \leftarrow$ assurance & 0.926416 & 59.832158 \\
\hline $2 \mathrm{P} 16 \leftarrow$ assurance & 0.792716 & 16.832030 \\
\hline $2 \mathrm{P} 17 \leftarrow$ assurance & 0.820830 & 24.561316 \\
\hline $2 \mathrm{P} 18 \leftarrow$ empathy & 0.780287 & 18.084508 \\
\hline $2 \mathrm{P} 19 \leftarrow$ empathy & 0.626910 & 4.935627 \\
\hline $2 \mathrm{P} 2 \leftarrow$ tangibles & 0.655564 & 5.108374 \\
\hline $2 \mathrm{P} 20 \leftarrow$ empathy & 0.802960 & 22.407331 \\
\hline $2 \mathrm{P} 21 \leftarrow$ empathy & 0.864385 & 31.957495 \\
\hline $2 \mathrm{P} 22 \leftarrow$ empathy & 0.755512 & 15.722911 \\
\hline $2 \mathrm{P} 3 \leftarrow$ tangibles & 0.842512 & 24.053056 \\
\hline $2 \mathrm{P} 4 \leftarrow$ tangibles & 0.431327 & 2.205204 \\
\hline $2 \mathrm{P} 5 \leftarrow$ reliability & 0.696141 & 11.161609 \\
\hline $2 \mathrm{P} 6 \leftarrow$ reliability & 0.780036 & 13.031310 \\
\hline $2 \mathrm{P} 7 \leftarrow$ reliability & 0.873246 & 26.246160 \\
\hline $2 \mathrm{P} 8 \leftarrow$ reliability & 0.748278 & 16.506445 \\
\hline $2 \mathrm{P} 9 \leftarrow$ reliability & 0.755462 & 9.927595 \\
\hline $5 \mathrm{P} 1 \leftarrow$ monetary & 0.939733 & 36.625475 \\
\hline $5 \mathrm{P} 10 \leftarrow$ value & 0.810433 & 21.785686 \\
\hline $5 \mathrm{P} 11 \leftarrow$ value & 0.784643 & 17.178982 \\
\hline $5 \mathrm{P} 12 \leftarrow$ value & 0.845262 & 33.507022 \\
\hline $5 \mathrm{P} 13 \leftarrow$ value & 0.516107 & 5.807412 \\
\hline $5 \mathrm{P} 14 \leftarrow$ value & 0.659261 & 10.467477 \\
\hline $5 \mathrm{P} 15 \leftarrow$ value & 0.611660 & 8.352136 \\
\hline $5 \mathrm{P} 16 \leftarrow$ value & 0.662731 & 10.318879 \\
\hline $5 \mathrm{P} 2 \leftarrow$ monetary & 0.948392 & 20.095252 \\
\hline $5 \mathrm{P} 3 \leftarrow$ monetary & 0.864379 & 15.418377 \\
\hline $5 \mathrm{P} 4 \leftarrow$ value & 0.779031 & 17.278598 \\
\hline 5P5 $\leftarrow$ value & 0.841202 & 23.859022 \\
\hline $5 \mathrm{P} 6 \leftarrow$ value & 0.745334 & 14.356103 \\
\hline $5 \mathrm{P} 7 \leftarrow$ value & 0.817656 & 21.824642 \\
\hline $5 \mathrm{P} 8 \leftarrow$ value & 0.775755 & 13.830023 \\
\hline $5 \mathrm{P} 9 \leftarrow$ value & 0.724701 & 13.820947 \\
\hline
\end{tabular}


employees/associates of the organization understand the specific security needs/regulatory requirements of their customers; the question 5P1 is: financial performance of the company (for example, net income, profits, and profit margins); the question 5P7 is: customer satisfaction with respect to security; and the question 5P13 is: how much in your opinion is the security related cost reduction for customers.

Therefore, considering the alpha values, AVE and loading values (as per Table 4), reliabilities of each item are acceptable.

\section{Testing of overall model}

The validity and reliabilities of each individual item have been established and as a next step we have proceeded to test the overall model in a two stage process. In the first stage the measurement model is evaluated and in the second stage the structural model is evaluated.

\subsection{First stage}

Reliability: composite reliability assesses the internal consistency of the constructs. The acceptable values for composite reliability are the same as those for Cronbach's alpha [70, 73, 74] (alpha should be greater than 0.70 for an acceptable scale). The values are acceptable as can be seen in Tables 5 and 6.

Validity — convergent and discriminate validity: average variance extracted (AVE) is used for establishing convergent validity. It reflects the average communality for each latent factor and in an adequate model, AVE should be greater than 0.50 [70] which can be seen in Tables 5 and 6 as acceptable values.

The cross loading test is used for evaluating the discriminate validity at an indicator level, where the loading of each indicator is expected to be greater than all of its cross-loadings. The latent variable predicts each variable in its construct better than the other constructs when the

Table 5 Actual

\begin{tabular}{lll}
\hline & AVE & Composite reliability \\
\hline Performance & 0.651096 & 0.779822 \\
Service quality & 0.749299 & 0.937206 \\
\hline
\end{tabular}

Table 6 Ratio-(actual to ideal)

\begin{tabular}{lll}
\hline & AVE & Composite reliability \\
\hline Performance & 0.662299 & 0.790729 \\
Service quality & 0.869073 & 0.970746 \\
\hline
\end{tabular}

correlations load is higher on the respective latent variables than other latent variables [73]. Within-construct item loadings should exceed the inter-construct cross loadings by at least $0.10[70,75]$ and hence the highlighted values as seen in Tables 7 and 8 are acceptable.

The discriminate validity at a construct level is investigated by comparing the square root of the average variance extracted (AVE) with the correlations between the variables and the correlation between different variables should be lower than the square root of the AVE [75] as can be seen acceptable in Tables 9 and 10 .

Thus, as part of the first stage, sufficient reliability and validity of the measurement model is established.

Table 7 Actual

\begin{tabular}{lllr}
\hline & Performance & Service quality & $T$ statistics \\
\hline A-Assuranee & 0.510344 & $\mathbf{0 . 8 8 4 7 6 7}$ & 34.358746 \\
A-Empathy & 0.558414 & $\mathbf{0 . 8 8 3 9 5 4}$ & 38.036846 \\
A-Reliability & 0.416175 & $\mathbf{0 . 8 6 0 9 3 6}$ & 22.476872 \\
A-Responsiveness & 0.502313 & $\mathbf{0 . 8 8 9 1 6 9}$ & 37.741185 \\
A-Tangibles & 0.415053 & $\mathbf{0 . 8 0 6 5 2 0}$ & 19.355049 \\
Monetary & $\mathbf{0 . 6 0 3 7 7 5}$ & 0.184767 & 4.225425 \\
Value & $\mathbf{0 . 9 6 8 3 2 2}$ & 0.589348 & 46.985015 \\
\hline
\end{tabular}

Table 8 Ratio-(actual to ideal)

\begin{tabular}{lllr}
\hline & Performance & Service quality & $T$ statistics \\
\hline Assurance & 0.281081 & $\mathbf{0 . 9 4 8 3 8 2}$ & 32.837001 \\
Empathy & 0.343445 & $\mathbf{0 . 9 3 6 4 2 7}$ & 32.295591 \\
Monetary & $\mathbf{0 . 6 4 2 8 7 3}$ & 0.127590 & 3.029331 \\
Reliability & 0.305819 & $\mathbf{0 . 9 2 9 5 6 4}$ & 20.725785 \\
Responsiveness & 0.253373 & $\mathbf{0 . 9 3 6 6 3 0}$ & 23.954954 \\
Tangibles & 0.262461 & $\mathbf{0 . 9 0 9 7 6 8}$ & 24.825542 \\
Value & $\mathbf{0 . 9 5 4 6 2 7}$ & $0.32 S 170$ & 23.215215 \\
\hline
\end{tabular}

Table 9 Actual

\begin{tabular}{lll}
\hline & Performance & Quality \\
\hline Performance & 0.806905 & \\
Quality & 0.559613 & 0.865621 \\
\hline
\end{tabular}

Table 10 Ratio-(actual to ideal)

\begin{tabular}{lll}
\hline & Performance & Quality \\
\hline Performance & 0.813818 & \\
Quality & 0.313618 & 0.932241 \\
\hline
\end{tabular}




\subsection{Second stage}

The coefficient of determination, $R^{2}$ is used for assessing the proportion of variance in the dependent latent variable that can be accounted for by the independent latent variables. The effect size of $R^{2}$ can be classified into three categories [76] based on its values-small (0.0196), medium (0.13), and large $(0.26)$.

The value of $R^{2}$, in our model, is 0.315032 in the actual case and 0.098596 in the ratio case as can be seen in Tables 11 and 12. In the actual case the effect size falls in the large category for performance, and in the ratio case the effect size falls in the small category for performance.

With respect to sign, magnitude and significance the path relationships were evaluated using a bootstrapping procedure where 5,000 sub samples were performed to evaluate the statistical significance of each path coefficient $[73,77]$. Critical $t$ values for a two-tailed test are 1.65 (significance $\quad$ level $=10 \%$ ), $1.96 \quad$ (significance level $=5 \%$ ), and 2.58 (significance level $=1 \%$ ) [75].

For the actual case, it clearly shows that a 100 points change in Information Security Service Quality will bring 55.9613 points change in organisation performance. The values are positive and are at significance level of $1 \%$ which is highly significant as seen in Table 13.

For ratio case it indicates that a 100 points change in information security service quality will bring 31.3618 points change in organisation performance. The values are

Table 11 Actual

\begin{tabular}{ll}
\hline & $R^{2}$ \\
\hline $\begin{array}{l}\text { Service quality } \\
\text { Performance }\end{array}$ & 0.315032 \\
\hline
\end{tabular}

Table 12 Ratio-(actual to ideal)

\begin{tabular}{ll}
\hline & $R^{2}$ \\
\hline $\begin{array}{l}\text { Service quality } \\
\text { Performance }\end{array}$ & 0.098596 \\
\hline
\end{tabular}

positive and are at significance level of $1 \%$ which is highly significant as seen in Table 14.

Thus the hypothesis that there is positive relationship collectively between elements of information security service quality and organisation performance is validated with this.

Further it is validated that information security service quality in an outsourcing company providing software services has a highly significant impact on the organisation performance.

The predictive relevance of the model is measured using the $Q^{2}$ statistic [78, 79]. A $Q^{2}$ greater than 0 means the model has predictive relevance. Values of $0.02,0.15$, and 0.35 signify small, medium, and large effects. Omission and estimation of data point depends on the chosen omission distance and it should be between 5 and 10 [80] (7 was selected). The cross-validated redundancy, should be used for the PLS path modelling approach $[80,81]$ for $Q^{2}$.

As can be seen in Tables 15 and 16, the $Q^{2}$ values are greater than 0 , thus the model has predictive relevance.

It can be seen that the values of $Q^{2}$ fall in the medium effect category for organisation performance in the actual case (Table 15) and in the small effect category for organisation performance in the ratio case (Table 16).

Thus the hypothesis that information security service quality in an outsourcing company providing software services has an impact on the organisation performance and can be predicted is validated.

\section{Discussion and limitation}

Our research shows that information security service quality drives organisation performance. It also shows that existing dimensions and instruments for service quality and organisation performance, available in literature, can be used by appropriate modification to reflect the context of information security. Software outsourcing business enterprises should focus on, amplify and commit to information security service quality at strategic, tactical, and operational levels if they want to achieve revenue expansion, completely satisfied customers and create trust.

Table 13 Actual

\begin{tabular}{llllll}
\hline & Original sample & Sample mean & Standard deviation & Standard error & $T$ statistics \\
\hline Service quality $\rightarrow$ performance & 0.559613 & 0.579510 & 0.102023 & 0.102023 & 5.485156 \\
\hline
\end{tabular}

Table 14 Ratio-(actual to ideal)

\begin{tabular}{llllll}
\hline & Original sample & Sample mean & Standard deviation & Standard error & $T$ statistics \\
\hline Service quality $\rightarrow$ performance & 0.313618 & 0.339691 & 0.110791 & 0.110791 & 2.830720 \\
\hline
\end{tabular}


Table 15 Actual

\begin{tabular}{ll}
\hline & $1-\mathrm{SSE} / \mathrm{SSO}$ \\
\hline Performance & 0.152806 \\
Service quality & 0.243573 \\
\hline
\end{tabular}

Table 16 Ratio-(actual to ideal)

1-SSE/SSO

Performance

0.059427

Service quality

0.114569

The limitation of this study is that it has only looked at the software outsourcing business enterprises in India. Future research should cover a larger sample from other service industries and also cover samples from multiple countries.

Given the growing significance of information and dependence on ICT in today's networked globe which is expected to explode in the future, information security is a crucial constituent which needs to be well thought-out and built as part of every aspect including service quality and we hope these findings would provide a step in that direction to other researchers and urge them to build upon our work in this field.

\section{References}

1. United Nations Conference on Trade and Development (UNCTAD) (2004) World investment report 2004: the shift towards services. United Nations, New York/Geneva

2. Hendricks KB, Singhal VR (1997) Does implementing an effective TQM program actually improve operating performance? Empirical evidence from firms that have won quality awards. Manag Sci 43(9):1258-1274

3. Conboy M (2013) Outsourcing makes the world a better place. Outsource Magazine, 23 Jan 2013

4. Bahl S, Wali OP, Kumaraguru P (2011) Information security practices followed in the Indian software services industry: an exploratory study. In: Cybersecurity summit (WCS), 2011 second worldwide, IEEEXplore, June 2011, pp 1-7

5. United Nations Publication (2002) Manual on statistics of international trade in services. Department of Economic and Social Affairs Statistics Division, Statistical Papers, Series M No. 86

6. Rajkumar TM, Mani RVS (2001) Offshore software development: the view from Indian suppliers. Inf Syst Manag 18(2):1-11

7. Agarwal S, Khaitan S, Shrivastava S, Banks M (2005) Destination India: offshore outsourcing and its implications. Comput Telecommun Law Rev 11(8):246-262

8. Aris S, Hj R, Syed A, Noor H, Mohamed A (2008) Conceptual framework on risk management in IT outsourcing projects. WSEAS Trans Inf Sci Appl 5(4):816-831

9. Benvenuto NA, Brand D (2005) Outsourcing-a risk management perspective", Information Systems Audit and Control Association (ISACA). Inf Syst Control J 5:35-40

10. Fink D (1994) A security framework for information systems outsourcing. Inf Manag Comput Secur 2(4):3-8
11. Gonzalez R, Gasco J, Llopis J (2006) Information systems offshore outsourcing: a descriptive analysis. Ind Manag Data Syst 106(9):1233-1248

12. Gonzalez R, Gasco J, Llopis J (2006) Information systems outsourcing: a literature analysis. Inf Manag 43(7):821-834

13. Gonzalez R, Gasco J, Llopis J (2009) Information systems outsourcing reasons and risks: an empirical study. Int J Soc Sci 4(3):180-191

14. Ilie V, Parikh M (2004) A process view of information systems outsourcing research: conceptual gaps and future research directions. In: Proceedings of the Tenth Americas. Association for Information Systems, p 448

15. Jorek N, Gott J, Battat M (2009) The shifting geography of offshoring. A.T. Kearney Global Services Location Index, Chicago

16. Khan N, CurrieWL, Weerakkody V, Desai B (2003) Evaluating offshore IT outsourcing in India: supplier and customer scenarios. In: Proceedings of the 36th Hawaii international conference on system sciences. System Sciences 2003, IEEE Computer Society.

17. Lacity MC, Willcocks LP, Feeny DF (1996) The value of selective sourcing. Sloan Manag Rev 37(3):13-25

18. Raisinghani MS, Starr B, Hickerson B, Morrison M, Howard M (2008) Information technology/systems offshore outsourcing: key risks and success factors. J Inf Technol Res 1(1):72-92

19. Saitta JA, Fjermestad J (2005) A basic model for information technology outsourcing. J Inf Sci Technol 2(4):7-29

20. Tafti MHA (2005) Risks factors associated with offshore IT outsourcing. Ind Manag Data Syst 105(5):549-560

21. Klepper R, Jones WO (1998) Outsourcing information technology, systems, services. Outsourcing information technology, systems, services. Prentice-Hall, Inc., Upper Saddle River

22. OECD (2012) Trade and labour market outcomes in Germany. In: Lippoldt D (ed) Policy priorities for international trade and jobs. OECD, Paris

23. Kaka NF, Sinha J (2005) An upgrade for the Indian IT services industry, special edition. McKinsey Quarterly, New Delhi, pp 84-89

24. Omachonu VK, Ross JE (2004) Principles of total quality, 3rd edn. CRC Press, Boca Raton

25. Kshetri N (2007) Institutional factors affecting offshore business process and information technology outsourcing. J Int Manag 13(1):38-56

26. Lin C, Chow WS, Madu CN, Kuei CH, Pei Yu P (2005) A structural equation model of supply chain quality management and organizational performance. Int J Prod Econ 96(3):355-365

27. Anuwichanont J, Mechinda P (2009) The impact of perceived value on spa loyalty and its moderating effect of destination equity. J Bus Econ Res 7(12):73-89

28. Wong A, Tjosvold D, Wong WYL, Liu CK (1999) Relationships for quality improvement in the Hong Kong China supply chain. Int J Qual Reliab Manag 16(1):24-41

29. Michael T, Fred W (1993) Customer intimacy and other value disciplines. Harv Bus Rev 71:84-93

30. Grover V, Cheon MJ, Teng JTC (1996) The effect of service quality and partnership on the outsourcing of information systems functions. J Manag Inf Syst 12(4):89-116

31. Urban W (2009) Service quality gaps and their role in service enterprises development. Technological and economic development of economy. Baltic J Sustain 15(4):631-645

32. Asubonteng P, McCleary KJ, Swan JE (1996) SERVQUAL revisited: a critical review of service quality. J Serv Mark 10(6):62-81

33. Parasuraman A, Berry LL, Zeithaml VA (1985) A conceptual model of service quality and its implications for future research. J Mark 49:41-50

34. Samat N, Ramayah T, Saad NM (2006) TQM practices, service quality, and market orientation: some empirical evidence from a developing country. Manag Res News 29(11):713-728 
35. Seth N, Deshmukh SG, Vrat P (2005) Service quality models: a review. Int J Qual Reliab Manag 22(9):913-949

36. Parasuraman A, Berry LL, Zeithaml VA (1988) SERVQUAL: a multiple item scale for measuring consumer perceptions of service quality. J Retail 64(1):12-40

37. Parasuraman A, Berry LL, Zeithaml VA (1991) Refinement and reassessment of the SERVQUAL scale. J Retail 67(4):420-450

38. Watson RT, Pitt LF, Kavan CB (1998) Measuring information systems service quality: lessons from two longitudinal case studies. MIS Q 22(1):61-79

39. Firesmith DG (2003) Common concepts underlying safety, security, and survivability engineering, No CMU/SEI-2003-TN033, Carnegi-Mellon Univ Pittsburgh PA Software Engineering Inst

40. Kahn BK, Strong DM, Wang RY (2002) Information quality benchmarks: product and service performance. Commun ACM 45(4ve): $184-192$

41. ISO/IEC 27001 (2009) Information technology—security techniques - information security management systems - requirements

42. Saint-Germain R (2005) Information security management best practice based on ISO/IEC 17799. Inf Manag J 39(4):60-66

43. Woody C (2005) Eliciting and analyzing quality requirements: management influences on software quality requirements, No. CMU/SEI-2005-TN-010. Software Engineering Institute, Carnegie Mellon University, Pittsburgh

44. Luor TT, Lu H-P, Tao Y-H, Lin TMY, Tung C-H (2008) Determinants of client intention of software outsourcing vendors: a model from Taiwan's financial industry. J Acad Bus Econ 8(1):159-166

45. Penn J, Forrester Research Inc. (2008) The state of enterprise IT security: 2008 to 2009. Business data services North America and Europe. Forrester Research Inc., Cambridge

46. Gazzini A, Holt M (2011) Limiting the impact of data breaches: the case of the Sony playstation network. Booz \& Company, New York, pp 1-12

47. Lodahl T, Redditt KL (2009) IT governance for IT effectiveness. Cut IT J 22(12):17-22

48. Adam EE, Corbett LM, Flores BE, Harrison NJ, Lee TS, Rho B-H, Ribera J, Samson D, Westbrook R (1997) An international study of quality improvement approach and firm performance. Int J Oper Prod Manag 17(9):842-873

49. Pryor MG, Toombs L, Anderson D, White JC (2010) What management and quality theories are best for small businesses? J Manag Mark Res 3:1-12

50. Melville N, Kraemer K, Gurbaxani V (2004) Review: information technology and organizational performance: an integrative model of IT business value. MIS Q 28(2):283-322

51. Cook LS, Verma R (2002) Exploring the linkages between quality system, service quality, and performance excellence: service providers' perspectives. Qual Manag J 9(2):44-56

52. Yacuzzi E (2005) A primer on governance and performance in small-and medium-sized enterprises. Documento de Trabajo, No. 293

53. Zeithaml VA (2000) Service quality, profitability, and the economic worth of customers: what we know and what we need to learn. J Acad Mark Sci 28(1):67-85

54. Samson D, Terziovski M (1999) The relationship between total quality management practices and operational performance. J Oper Manag 4(17):393-409

55. Wirtz J (1998) Development of a service guarantee model. Asia Pac J Manag 15(1):51-75

56. Zisis P, Garefalakis A, Sariannidis N (2009) The application of performance measurement in the service quality concept: the case of a Greek service organization. J Money Invest Bank Issue 9:21-47

57. Golder PN, Mitra D, Moorman C (2012) What is quality? An integrative framework of processes and states. J Mark 76(4):1-23
58. Jones TO, Sasser WE Jr (1995) Why satisfied customers defect. Harv Bus Rev 73(6):88-99

59. Aranda DA (2003) Service operations strategy, flexibility and performance in engineering consulting firms. Int $\mathrm{J}$ Oper Prod Manag 23(11):1401-1421

60. Rust RT, Moorman C, Dickson PR (2002) Getting return on quality: revenue expansion, cost reduction, or both? J Mark 66:7-24

61. Ringle CM, Wende S, Will A (2005) SmartPLS 2.0 (beta). http://www.smartpls.de. Accessed 1 Sept 2012

62. Wold H (1989) Introduction to the second generation of multivariate analysis, theoretical empiricism. Paragon House, New York, pp 7-11

63. Jöreskog KG, Wold H (1982) The ML and PLS techniques for modeling with latent variables: historical and comparative aspects, systems under direct observations: causality, structure, prediction, part I. North-Holland Publication, Amsterdam, pp 263-270

64. Chin WW (1988) The partial least squares approach to structural equation modelling. In: Marcoulides GA (ed) Modern methods for business research. Lawrence Erlbaum Associates, New Jersey

65. Chin WW, Marcolin BL, Newsted PR (1996) A partial least squares latent variable modeling approach for measuring interaction effects: results from a Monte Carlo simulation study and voice mail emotion/adoption study. In: DeGross JI, Jarvenpaa S, Srinivasan A (eds) Proceedings of the seventeenth international conference on information systems

66. Chin WW, Newsted PR (1999) Structural equation modeling analysis with small samples using partial least squares. In: Hoyle RH (ed) Statistical strategies for small sample research. Sage Publications, Thousand Oaks, pp 307-342

67. Goodhue D, Lewis W, Thompson R (2006) PLS, small sample size, and statistical power in MIS research. In: Proceeding of the 39th Hawaii international conference on system sciences, vol 8. IEEE

68. Lehner F, Haas N (2010) Knowledge management success factors-proposal of an empirical research. Electron J Knowl Manag 8(1):79-90

69. Cronbach LJ (1951) Coefficient alpha and the internal structure of tests. Psychometrika 16(3):297-334

70. Fornell C, Larcker DF (1981) Evaluating structural equation models with unobservable variables and measurement error. J Mark Res 18:39-50

71. Chin WW (1998) Issues and opinion on structural equation modelling. MIS Q 22(1):7-16

72. Churchill GA (1979) A paradigm for developing better measures of marketing constructs. J Mark Res 16(1):64-73

73. Chin WW (1998) The partial least squares approach for structural equation modelling. In: Marcoulides GA (ed) Modern methods for business research, methodology for business and management. Lawrence Erlbaum Associates, Inc., Mahwah, pp 295-336

74. Höck M, Ringle CM (2010) Local strategic networks in the software industry: an empirical analysis of the value continuum. Int J Knowl Manag Stud 4(2):132-151

75. Gefen D, Straub D (2005) A practical guide to factorial validity using PLS-graph: tutorial and annotated example. Commun Assoc Inf Syst 16:91-109

76. Kotrlik J, Williams H (2003) The incorporation of effect size in information technology, learning, and performance research. Inf Technol Learn Perform J 21(1):1-7

77. Henseler J, Ringle CM, Sinkovics RR (2009) The use of partial least squares path modeling in international marketing. In: Sinkovics RR, Ghauri PN (eds) Advances in international marketing, vol 20, 1st edn. Emerald Group, Bingley, pp 277-319

78. Geisser S (1974) A predictive approach to the random effect model. Biometrika 61(1):101-107 
79. Stone M (1974) Cross-validatory choice and assessment of statistical predictions. J R Stat Soc Ser B (Methodol) 36:111-147

80. Hair JF, Ringle CM, Sarstedt M (2011) PLS-SEM: indeed a silver bullet. J Mark Theory Pract 19(2):139-152
81. Wold HO (1982) Softmodeling: the basic design and some extensions. In: Jöreskog KG, Wold HO (eds) Systems under indirect observations, Part II, chapter 1. North-Holland Publishing Co., Amsterdam, pp 1-54 